\title{
Redox Stimulation of Human THP-1 Monocytes in Response to Cold Physical Plasma
}

\author{
Sander Bekeschus, Anke Schmidt, Lydia Bethge, Kai Masur, Thomas von Woedtke, \\ Sybille Hasse, and Kristian Wende
}

\author{
Leibniz Institute for Plasma Science and Technology (INP Greifswald), Felix-Hausdorff-Straße 2, 17489 Greifswald, Germany \\ Correspondence should be addressed to Sander Bekeschus; sander.bekeschus@gmail.com
}

Received 22 May 2015; Revised 17 July 2015; Accepted 22 July 2015

Academic Editor: Manuela Malatesta

Copyright (c) 2016 Sander Bekeschus et al. This is an open access article distributed under the Creative Commons Attribution License, which permits unrestricted use, distribution, and reproduction in any medium, provided the original work is properly cited.

\begin{abstract}
In plasma medicine, cold physical plasma delivers a delicate mixture of reactive components to cells and tissues. Recent studies suggested a beneficial role of cold plasma in wound healing. Yet, the biological processes related to the redox modulation via plasma are not fully understood. We here used the monocytic cell line THP-1 as a model to test their response to cold plasma in vitro. Intriguingly, short term plasma treatment stimulated cell growth. Longer exposure only modestly compromised cell viability but apparently supported the growth of cells that were enlarged in size and that showed enhanced metabolic activity. A significantly increased mitochondrial content in plasma treated cells supported this notion. On THP-1 cell proteome level, we identified an increase of protein translation with key regulatory proteins being involved in redox regulation (hypoxia inducible factor $2 \alpha$ ), differentiation (retinoic acid signaling and interferon inducible factors), and cell growth (Yin Yang 1). Regulation of inflammation is a key element in many chronic diseases, and we found a significantly increased expression of the anti-inflammatory heme oxygenase 1 (HMOX1) and of the neutrophil attractant chemokine interleukin-8 (IL-8). Together, these results foster the view that cold physical plasma modulates the redox balance and inflammatory processes in wound related cells.
\end{abstract}

\section{Introduction}

Plasma is generated by substantial energy input to a gas, thereby creating a "fourth state of matter" [1]. Plasma contains active and reactive components of many kinds including electrons, ions, and reactive oxygen and nitrogen species (ROS and RNS) as well as ultraviolet (UV), visible, and infrared radiation [2]. Apart from naturally occurring plasma, for example, lightning, fire, or Aurelia borealis, plasma is also created artificially. For plasma jets, such as the one used in the present study (kiNPen), the reactive components of the plasma can be delivered directly and in a controlled manner to cells and tissues without inducing thermal damage [3]. In the device (or kiNPen), the noble gas argon is excited at a central high voltage electrode (AC, several $\mathrm{kV}, \approx 1 \mathrm{MHz}$ ). This creates nonequilibrium plasma that contains hot and reactive electrons and relatively cold argon ions in a bulk of nonionized gas atoms that govern the overall temperature [4]. The electrons and argon ions [5] in turn react with ambient oxygen or nitrogen molecules to form ROS/RNS [6]. This may be of therapeutic benefit in pathological skin conditions, as first small-scale clinical studies supported the notion that chronic wounds displayed an improved healing signature after exposure to ROS/RNS generating plasma [7-9].

Cells of the immune system are central players in the regulation of all wound healing phases [10]. During the inflammatory phase, professional phagocytes are attracted via cytokines and reactive molecules from the vasculature to the wound bed where they eradicate invading microorganisms [11]. Among them are monocytes which in situ differentiate into macrophages [12]. Macrophages also dominate the center of chronic ulcers and can potently generate reactive species [13]. These cells have key regulatory functions which are reflected by, for example, the phagocytosis of dead cells [14] and debris as well as their release of cytokines [15] and other wound healing-related proteins, such as heme oxygenase 1 (HO-1) [16]. In particular, interleukin-8 (IL-8) is a central molecule in initiating the inflammatory wound 
healing phase [17] and its secretion was previously shown to be accented by reactive species, such as hydroxyl radicals [18].

Wound healing is highly redox-controlled [19]. Almost all cells of the wound microenvironment utilize oxygen to generate reactive species, and at low concentration these species seem to be required for proper healing [20]. It is hypothesized that plasma may trigger similar responses in cells. Yet, the mechanisms and biological processes following exposure to plasma are not fully understood [21]. Accordingly, we investigated the neoplastic cell line THP-1 monocytes as a model to study the effects of a plasma-based redox modulation. We identified an increase in free thiol content, cell proliferation, and metabolic activity, arguing for a priming of these cells which was further manifested by significant changes in protein expression as analyzed by mass spectrometry based proteomic tools. We further identified an altered inflammatory signature. Our results implicate a potential significance of redox intonations by plasma that may help to further understand its impending benefit in human skin pathologies.

\section{Materials and Methods}

2.1. Cell Culture. THP-1 monocytes (ACC 16, DSMZ, Germany) were cultured in RPMI1640 medium (Lonza, Switzerland) containing $10 \%$ bovine calf serum (Sigma, USA), 2\% glutamine (Pan-Biotech, Germany), and 1\% penicillin/streptomycin (Lonza, Switzerland). For total protein expression using stable isotope labeling (SILAC), cells were labeled for at least three passages in complete RPMI containing $10 \%$ of dialyzed bovine calf serum with either both isotopically labeled arginine and lysine $\left({ }^{13} \mathrm{C}_{6}^{15} \mathrm{~N}_{4}\right.$ arginine and ${ }^{13} \mathrm{C}_{6}^{15} \mathrm{~N}_{2}$ lysine, Cambridge Isotopes, USA) or regular amino acids.

2.2. Plasma Source and Treatment. The atmospheric pressure argon plasma jet kiNPen 11 (neoplas tools GmbH, Germany) was used. It was operated with five standard liters per minute $(\mathrm{s} \operatorname{lm})$ of argon gas (Air Liquide, France) and its flux was controlled using a mass flow controller (MKS instruments, Germany). The jet is equipped with a ceramic capillary (inner radius of $0.8 \mathrm{~mm}$ ) and an inner pin-type high-frequency electrode $(\mathrm{AC} \approx 1 \mathrm{MHz}$, several $\mathrm{kV})$. Cells were indirectly plasmatreated in experiments where RNA and protein were collected for real-time PCR or mass spectrometry, respectively. Here, $5 \mathrm{~mL}$ of cell culture medium in a $60 \mathrm{~mm}$ dish was plasmatreated and was subsequently added to $1 \times 10^{6}$ pelleted THP1 cells. For direct plasma treatment in all other experiments, $5 \mathrm{~mL}$ of cell suspension $\left(0.2 \times 10^{6} / \mathrm{mL}\right.$ of medium $)$ was added to a $60 \mathrm{~mm}$ plastic dish (Sarstedt, Germany) and exposed to plasma. In both regimes and using a computer-controlled $x y z$-table (S-400, CNC step, Germany), the jet hovered over the sample in a meandering fashion for the indicated time length. A predetermined amount of destilled water was added after treatment to compensate evaporation. The direct and indirect approaches were previously compared and found to have similar effects. Using the same plasma source, this accounts for toxicity in human PBMC [22] and effects on metabolic activity and proliferation in feline epithelial cells [23]. Analogous results were obtained for other sources using human epithelial cells [24] as well as for inactivating bacteria [25].

2.3. Metabolic Activity Assay. THP-1 monocytes were plasma-treated, aliquoted in 96-well plates (Sarstedt, Germany), and incubated for $72 \mathrm{~h}$ at $37^{\circ} \mathrm{C}$. Resazurin (Alfa Aesar, USA) was added (final concentration $200 \mu \mathrm{M}$ ), and cells were incubated for $4 \mathrm{~h}$. In active cells, $\mathrm{NADH}^{+}$is generated during the cellular metabolism which sponsors the transformation of resazurin to its fluorescent product resorfurin [26]. The latter can be detected measuring its fluorescence at $590 \mathrm{~nm}$ (excitation wavelength $530 \mathrm{~nm}$ ) using a microplate reader (M200 pro, Tecan, Austria).

2.4. Flow Cytometry. To assess intracellular redox changes, THP-1 monocytes were stained with $2 \mu \mathrm{M} \mathrm{CM}-\mathrm{H}_{2}$ DCF-DA (Life Technologies, USA) prior to plasma-treatment and subsequent analysis by flow cytometry (Gallios, Beckman-Coulter, USA). Also, cells were plasma-treated, collected at various incubation times, and stained with $10 \mu \mathrm{M}$ of the ThiolTracker probe (Life Technologies) to assess the intracellular reduced thiol content. Apoptosis was investigated as previously described [27]. Briefly, cells were plasma-treated and after $24 \mathrm{~h}$ they were incubated in Annexin $\mathrm{V}$ binding buffer containing Annexin V FITC (BioLegend, USA) and 4',6-diamidin-2phenylindol (DAPI, Sigma, USA). Alternatively, cells were fixed in ethanol and stained with DAPI to analyze THP-1 cell cycle. To analyze the metabolic activity per cell, resorfurin fluorescence was measured, and DAPI was added prior to cell enumeration using volumetric flow cytometry (Attune, Life Technologies). Viable cell counts were related to total fluorescence obtained by the resazurin-reduction assay. Mean forward and side scatter fluorescence intensity was evaluated as well. To determine mitochondrial content, cells were stained with $0.5 \mu \mathrm{M}$ MitoTracker red FM (Life Technologies) $72 \mathrm{~h}$ after plasma treatment.

2.5. Global Protein Expression. Proteomic analysis was carried out as previously described [28]. Briefly, SILAC-labeled THP- 1 cells were exposed to plasma-treated ( $3 \mathrm{~min}$ ) medium and cellular protein was collected $24 \mathrm{~h}$ later. Proteins were fractionated using SDS gel electrophoresis and in-gel protein digestion was performed. Peptides were analyzed by nanoLC/MS (Proxeon, Denmark), and the eluent was ionized by electrospray ionization and examined using a TripleTOF 5600 (AB Sciex, USA) mass spectrometer. Data were processed using ProteinPilot 4.5 software (AB Sciex) and Ingenuity Pathway Analysis (Qiagen, USA). Between 2200 and 2700 human proteins from about 60,000 peptides were identified out of 240,000 mass spectra. Candidates were selected upon their significant involvement in pathways of metabolisms and/or redox stress as well as on statistical criteria ( $\geq \pm 1.5$ fold expression). Additionally, data were analyzed through the use of Ingenuity Pathway Analysis (IPA, Qiagen) and free web based applications (PANTHER and Universal Protein Resource). 

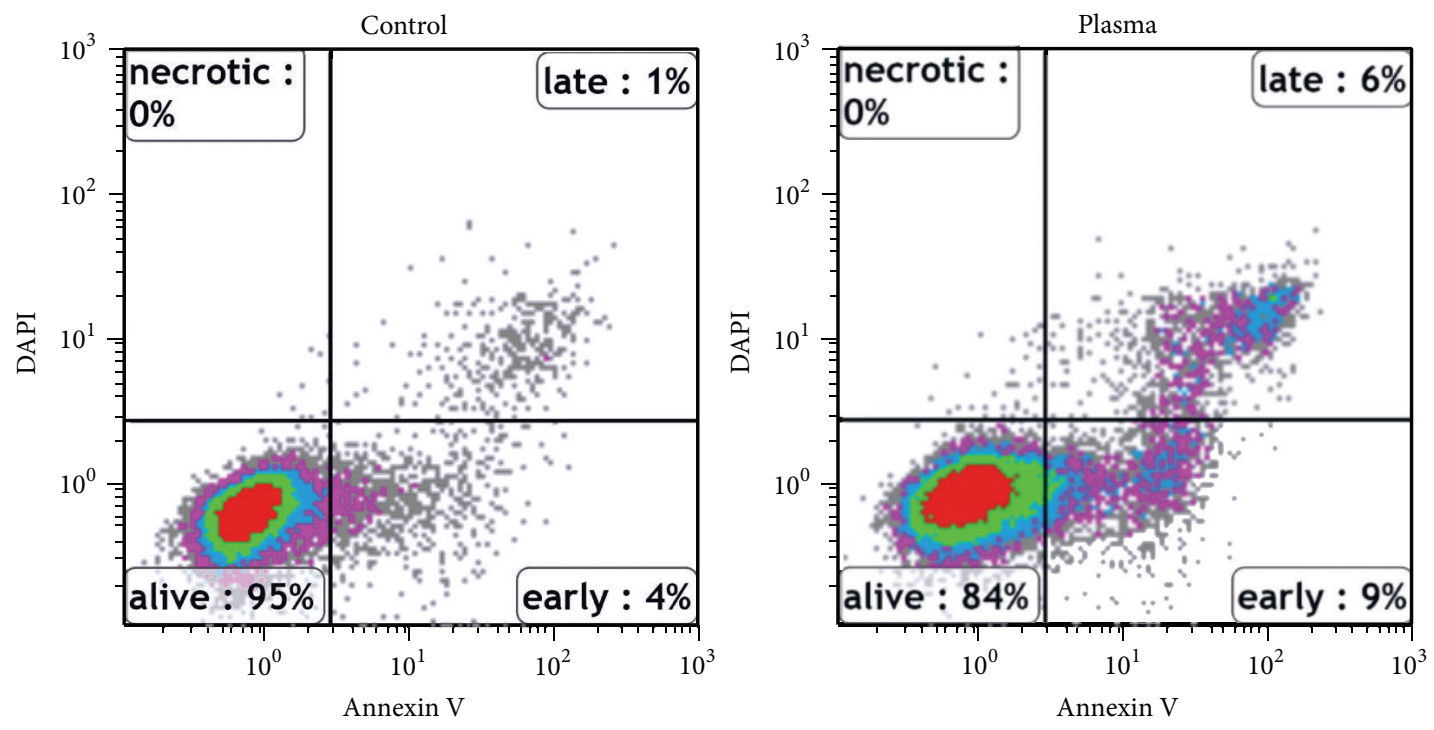

(a)

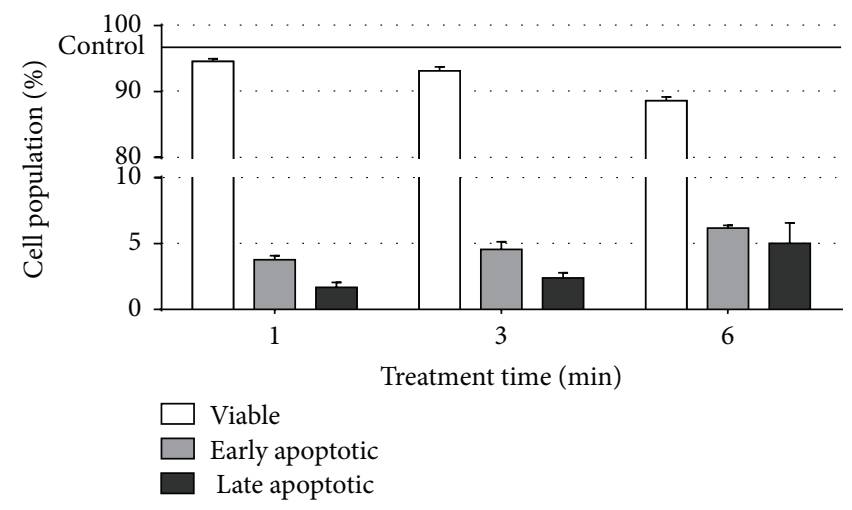

(b)

Figure 1: Analysis of THP-1 cell apoptosis. THP-1 monocytes were plasma-treated (6 min). Percentages of viable as well as early and late apoptotic cells were analyzed (a) and quantitated (b) by flow cytometry using Annexin V and DAPI. "Ctrl" represents percent of viable cells in untreated samples; percentages of viable and early and late apoptotic cells add up to 100. Data are shown as one representative (b) or mean + S.E. (b) of five independent experiments.

2.6. Real-Time PCR of IL-8 and HMOX1. THP-1 cells were exposed to plasma-treated medium and incubated for $12 \mathrm{~h}$ or $24 \mathrm{~h}$. Cells were harvested and mRNA was isolated (RNA-Mini Kit; Bio\&Sell, Germany). Complementary DNA (cDNA) was generated from total RNA using transcriptor first strand cDNA synthesis kit and T4 DNA polymerase for second strand synthesis (both from Roche, Switzerland). For quantitative polymerase chain reaction, the real-time ready catalogue assay kit containing $I L-8$ and $H M O X 1$ primers was utilized, and samples were analyzed using a LightCycler 480 II (all Roche).

2.7. Cytokine Detection. THP-1 cells were incubated for $24 \mathrm{~h}$ after plasma treatment. Supernatants were analyzed using an IL-8 (BioLegend) ELISA and a multianalyte inflammatory cytokine ELISA array (Qiagen). Sample values were normalized to control values and displayed as fold change to control.
2.8. Statistics. Experiments were repeated at least three times. Values were displayed as arithmetic mean. For MitoTracker and ThiolTracker fluorescence and for IL-8 and HMOX1 expression studies, Student's $t$-test was applied. For comparison in all other experiments, one-way ANOVA with Dunnett posttesting was utilized. Significance levels were indicated as follows: ${ }^{*} \alpha=0.05,{ }^{* *} \alpha=0.01$, and ${ }^{* * *} \alpha=0.001$.

\section{Results and Discussion}

3.1. Plasma Altered the Cellular Redox State without Major Apoptosis Induction. In this study, we investigated whether exposure to cold physical plasma affected THP-1 cell viability, metabolic activity, and function. THP-1 cell apoptosis was studied (Figure 1(a)), and viability was compromised only to a minor extent (Figure 1(b)). This is in line with peripheral blood monocyte viability being only marginally affected 


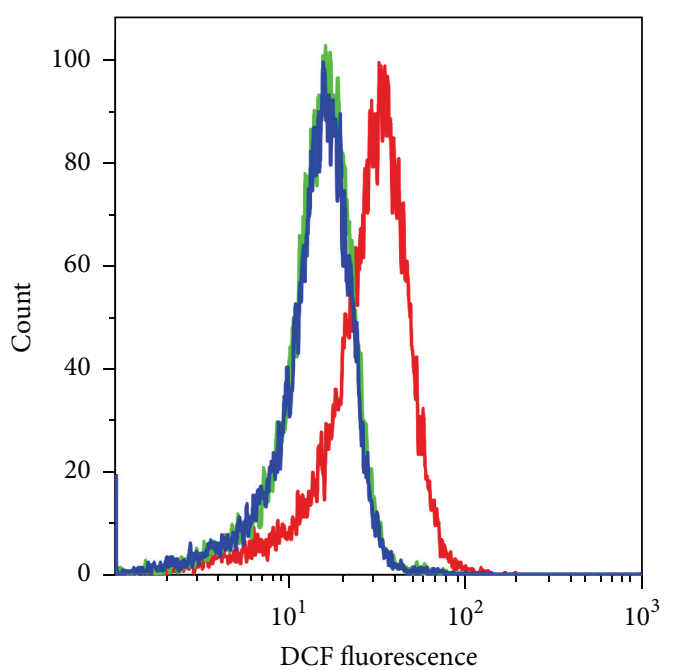

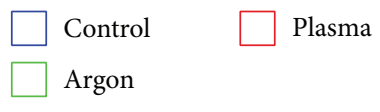

(a)

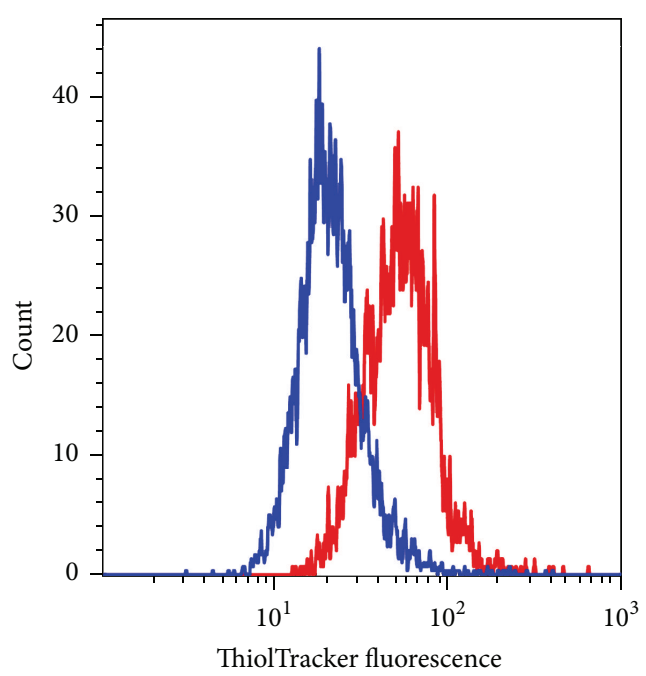

ThiolTracker fluorescence

Control

Plasma

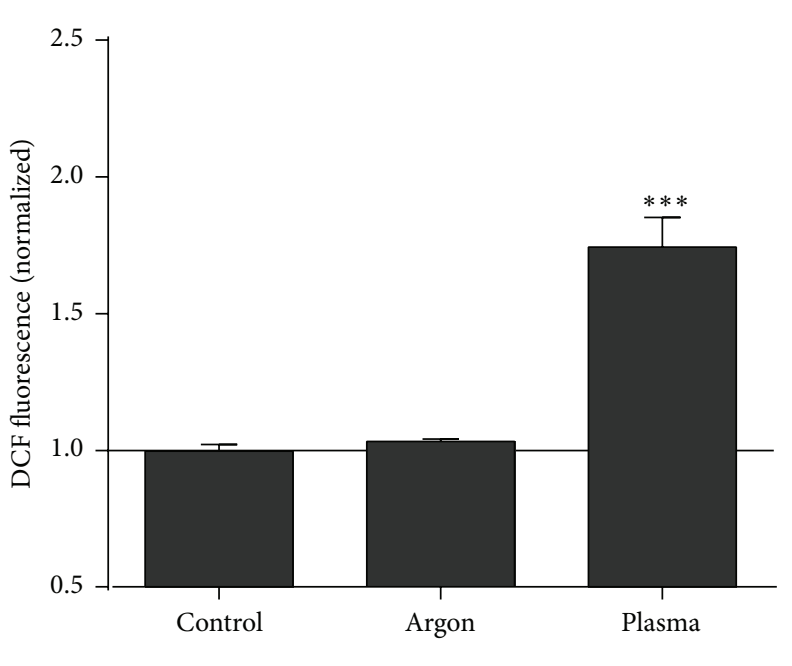

(b)

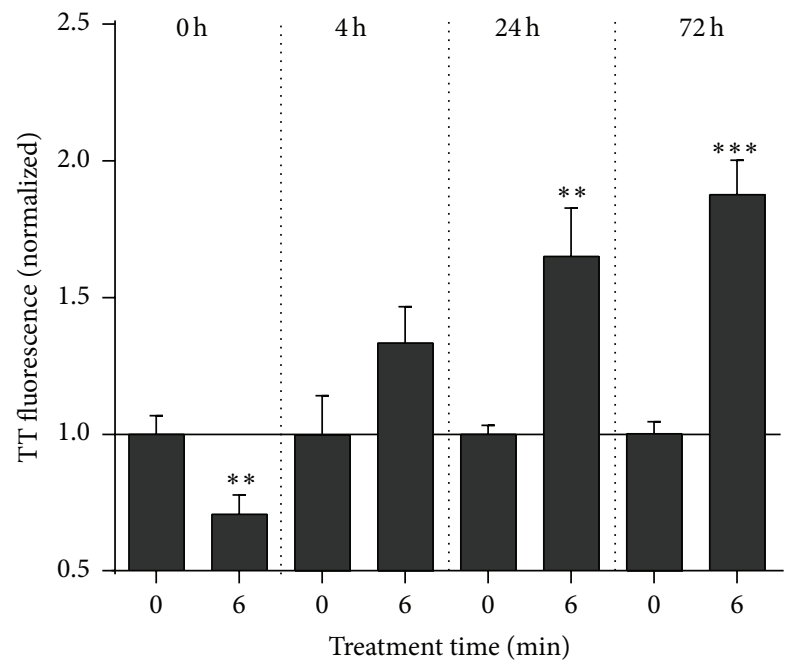

(d)

FIGURE 2: Analysis of redox changes in THP-1 cells. THP-1 cells were stained with CM- $\mathrm{H}_{2}$ DCF-DA and plasma-treated (3 min) to evaluate intracellular redox changes by flow cytometry $(\mathrm{a}, \mathrm{b})$. THP-1 cells were plasma-treated, and cells were stained at different time point with ThiolTracker dye to examine their total reduced thiol content ((c), shown for $72 \mathrm{~h}$ ) by flow cytometry (d). Data are shown as one representative $(\mathrm{a}, \mathrm{c})$ or mean + S.E. $(\mathrm{b}, \mathrm{d})$ of three independent experiments.

by plasma [27]. Yet, plasma did induce changes in the cellular redox state. Immediately following treatment, THP1 cells showed a significant $(P<0.001)$ increase in DCF fluorescence (Figures 2(a) and 2(b)). Although DCF is regarded as a general redox probe, it is highly sensitive to hydroxyl radicals [29]. These may have been formed in the Fenton reaction of plasma-derived hydrogen peroxide [30] with metals being inevitably present in biological systems [31]. We asked next whether plasma-derived reactive species also affected the cells' antioxidative defense. Here, glutathione is a central molecule which constitutes and regenerates the majority of free thiols in cells to maintain redox homeostasis [32]. The intracellular free thiol content was significantly $(P<0.01)$ decreased immediately following exposure to plasma whereas thiol levels were substantially elevated hours and days after plasma treatment (Figures 2(c) and 2(d)). This argues for a swiftly augmented redox defense in response to plasma with only little induction of apoptosis. This 


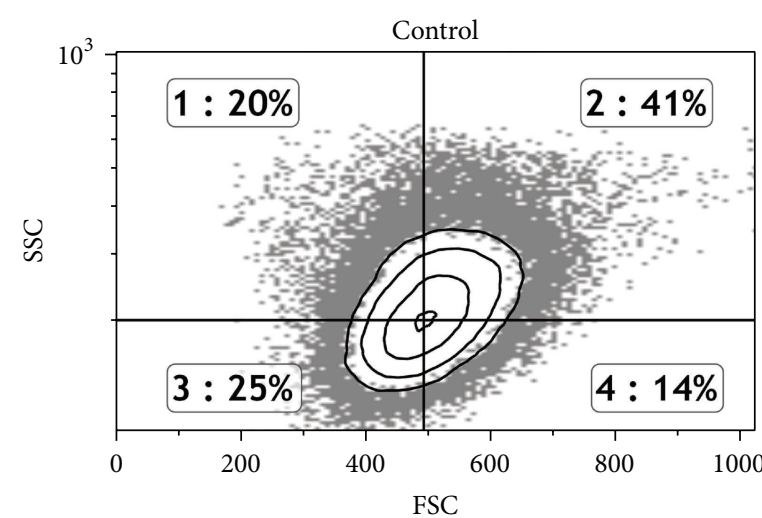

(a)

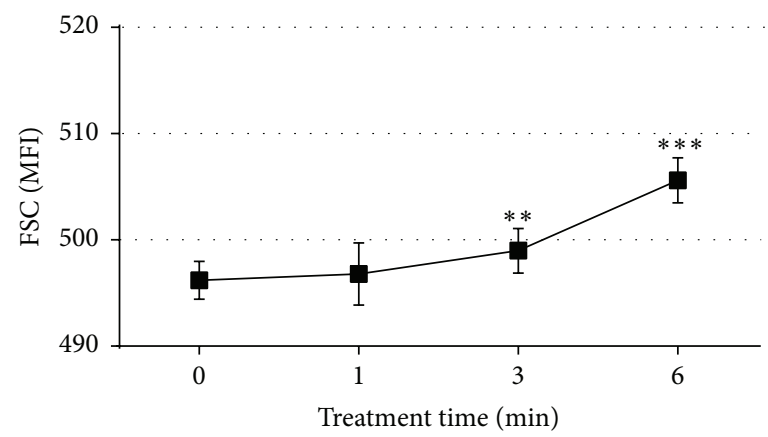

(c)

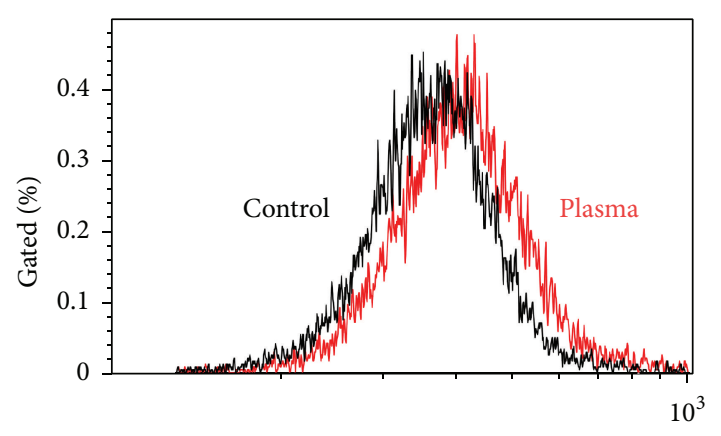

MitoTracker red fluorescence

(e)

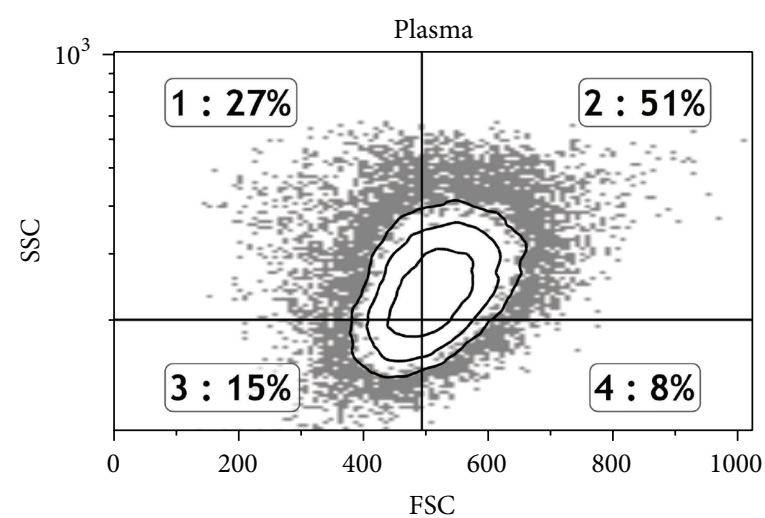

(b)

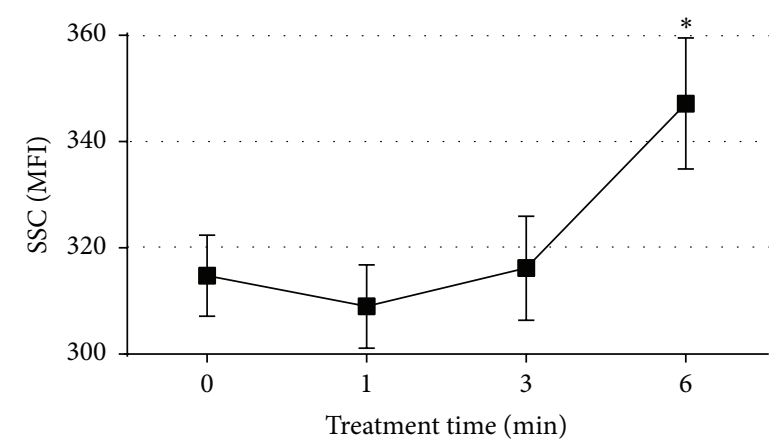

(d)

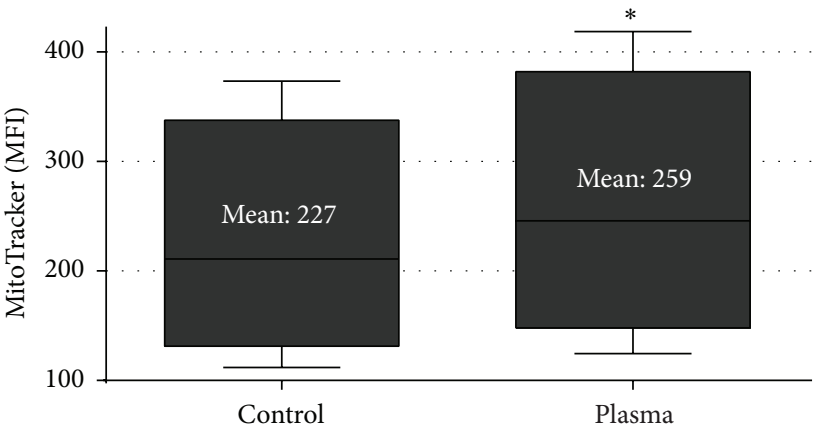

(f)

FIGURE 3: Analysis of THP-1 cell size and mitochondrial content. THP-1 monocytes were plasma-treated. After $72 \mathrm{~h}$, forward (FS) and side scatter (SSC) distribution ( $a, b)$ and mean fluorescence intensity (MFI) thereof $(c, d)$ were analyzed in viable cells using flow cytometry. MitoTracker red fluorescence indicative of total mitochondrial content was assessed in viable cells (f) $72 \mathrm{~h}$ after plasma treatment. Data are shown as one representative (a, b, e), mean + S.E. (c, d), or boxplot (5-95 percentile, (f)) of three independent experiments.

may be explained by THP-1 cells being derived from an acute monocytic leukemia (AML), and an excessive constitutive ROS production combined with an impaired p38-MAPK and ROS-mediated apoptosis signaling was found in AMLs of oncological patients [33]. Moreover, GSH decrease was also followed by a rebound increase as an adaptive response to oxidative stress in epithelial cells [34], underlining our results, and suggested an adaptation in THP-1 cells following plasma. We subsequently investigated alterations in the cells' morphology and metabolic activity after plasma treatment.

\subsection{Plasma Enhanced Cell Size and Stimulated Cellular Pro-} liferation. Compared to control cells (Figure 3(a)), plasmatreated cells (Figure 3(b)) displayed a small but significant enhancement of mean forward scatter (attributed to the cells' size, Figure 3(c)) and side scatter (attributed to the cells' granularity and membrane irregularity, Figure 3(d)). This correlated with mitochondrial content (Figure 3(e)) that was significantly increased in plasma-treated cells as well (Figure 3(f)), possibly pointing to an altered metabolic activity. Indeed, we found a significant elevation $(P<0.003)$ 
of cellular respiration for short exposure to plasma (1 min). By contrast, total metabolic activity was significantly $(P<$ $0.001)$ decreased after extended (6 min) plasma treatment (Figure 4(a)). The same cells that were subjected to the assessment of metabolic activity were subsequently analyzed by volumetric flow cytometry and viable cells were counted. Again, we found a significant $(P<0.001)$ increase in cell numbers for short exposure times and a significant decrease $(P<$ 0.001 ) for longer exposure times to plasma (Figure 4(b)). Based on these data, we calculated the metabolic activity on a per-cell basis by combination of the total fluorescence divided by the total number of viable cells (Figure 4(c)). For short exposure times there was no difference compared to untreated controls. On the contrary, the per-cell metabolic activity was significantly $(P<0.001)$ enhanced in cells that were exposed to plasma for $6 \mathrm{~min}$. Supplementation of fresh media during the incubation time yielded similar results and hence the elevated metabolism was not a consequence of nutrient limitation in control cells (data not shown). The decrease in total cell numbers (Figure 4(b)) was reflected by a significant $(P<0.001)$ G2 arrest (Figures 4(d) and 4(e)) $24 \mathrm{~h}$ but not $72 \mathrm{~h}$ (data not shown) after plasma treatment.

These results suggest that exposure to plasma may have stimulated THP-1 cells, eventually leading to enhanced proliferation for short exposure times. Reactive species delivered to the cells via the plasma altered the intracellular redox state and consequently stimulated growth. This may be reflected by the finding of others who suggested a role of redox changes in, for example, thioredoxin or Id3 in growth stimulation [35, 36]. It was reported that redox modifications in THP-1 monocytes lead to macrophage differentiation [37] which may account for the increase observed in cell size (Figure 3(c)) and metabolic activity (Figure 4(c)). Indeed, THP-1 cell activations via, for example, mitogens increase cell size as well [38]. Yet, mitogen-activated and THP-1 cell-derived macrophages display a distinct surface marker signature (e.g., elevated expression of CD33, CD45, CD49b, CD49d, CD81, and CD141) which was not present on plasma-treated THP-1 cells (data not shown). This argues against a role of plasma in induction of THP-1 cell differentiation. Oxidative stress was also shown to support an accumulation of THP-1 cells in the G2 phase of the cell cycle [39] which supports our findings (Figure 4(e)) and may explain the lower proliferation found after prolonged exposure to plasma (Figure 3(b)). A linkage between the enhanced metabolic activity and the elevated mitochondrial content (Figure 3(f)) is unlikely due to the monocytes' glycolytic nature [40]. It was suggested that monocytes utilize mitochondria to generate ROS for signaling purposes and not mainly for ATP generation [41]. This would imply a combined extrinsic (plasma) and intrinsic (mitochondria) ROS generation, possibly affecting redox signaling and/or other biological responses observed in this study. Finally, growth promotion of plasma-treated cells may be a consequence of elevated GSH levels (Figure 2(d)) protecting from ROS generated during proliferation [42].

3.3. Global Protein Expression Screening. Next, proteome analysis was carried out to further elucidate the THP-1 cell
TABLE 1: Differential expression of proteins complexed in metabolic and redox processes after plasma treatment. Fold regulation of relevant candidate protein expression identified from global proteomic profiling of THP- 1 cells and $24 \mathrm{~h}$ after exposure to plasma-treated medium. Data are presented as mean and range of three independent experiments.

\begin{tabular}{lcc}
\hline Short name/ID & Fold change & Pathway/task \\
\hline EPAS1 (Q99814) & $+4.0 \pm 0.7$ & Transcription factor \\
YY1 (P25490) & $+3.0 \pm 0.3$ & Cell cycle control \\
CRABP1 (P29762) & $+1.9 \pm 0.2$ & Retinoic acid signaling \\
SUGT1 (Q9Y2Z0) & $+1.9 \pm 0.3$ & Protein ubiquitination \\
STUB1 (Q9UNE7) & $+1.7 \pm 0.2$ & Protein ubiquitination \\
SOD2 (P04179) & $-1.5 \pm 0.1$ & Redox balancer \\
IRF8 (Q02556) & $-1.6 \pm 0.2$ & Interferon signaling \\
\hline
\end{tabular}

protein response to plasma. In plasma-treated THP-1 monocytes, total protein expression was increased by 1.05 -fold, paralleling the observed increase in cell size (Figure 3). An increase of protein translation was also suggested by the finding that the dominant pathways regulated after plasma involved ribosomal protein translation (eIF2 signaling and eIF4/p706K signaling) [43]. Simultaneously, cellular protein degradation was elevated, indicated by an increased expression of several key members of the ubiquitin/proteasome pathway, such as SUGT1 and STUB1 (Table 1) $[44,45]$.

These observations point to an anticipated protein stress response triggered by plasma and subsequent changes in the THP-1 monocyte redox state. This notion is further supported by the finding that the endothelial PAS domain-containing protein 1 (EPAS1, also known as hypoxia inducible factor$2 \alpha$ ) was highly regulated after plasma (Table 1). Like HO-1, EPAS1 is central in the maintenance of redox homeostasis and is moreover linked to superoxide dismutase (SOD) activity [46]. After plasma treatment, we found a decrease in mitochondrial-resident SOD (SOD2, Table 1). Although SOD2 is a protector against oxidative stress, previous work had found downregulation during the physiological wound healing process in rats [47]. Along with our findings, decreased levels were also reported in response to sublethal oxidative stress in neuronal cells [48]. In oxidatively challenged rats, Yin Yang 1 (YY1), a zinc finger transcription factor, was strongly increased [49] which correlates with our results (Table 1). YY1 is central in cell cycle progression and resistance to apoptotic stimuli [50] and its upregulation in macrophages is associated with an increased expression of cyclooxygenase 2 (COX2) [51]. COX2 is a hallmark of tissue injury and inflammation. Thus, the increase of YY1 expression after plasma may represent the perception of a danger stimulus by THP-1 cells. This may be reflected by changes in the inflammatory signature (Figure 5) and the decrease of interferon regulatory factor 8 expression (IRF8, Table 1) which may indicate the effort to control interleukin production and overshooting cell activation [52, 53]. YY1 also controls respiratory chain expression and mitochondrial activity $[54,55]$ and may have a role in the modulation of the metabolic activity observed (Figure 4(c)). 


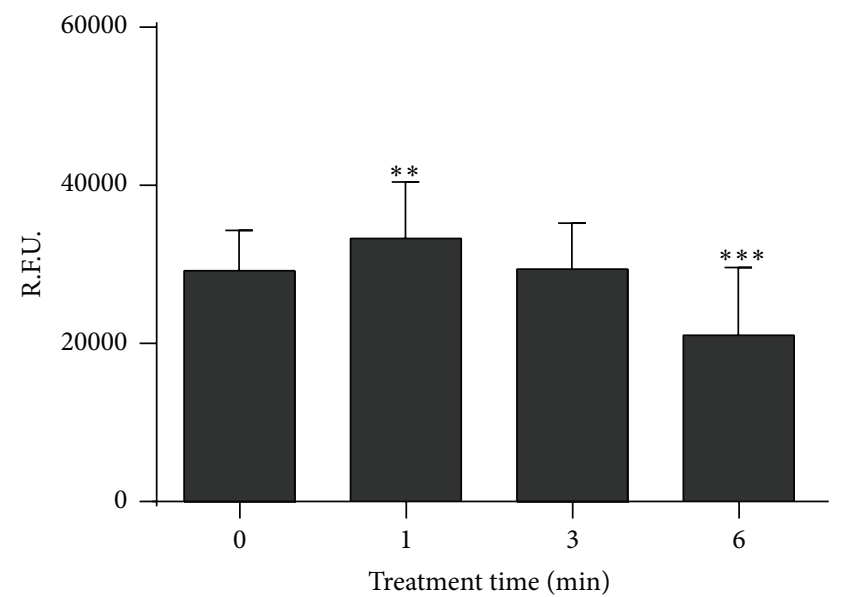

(a)

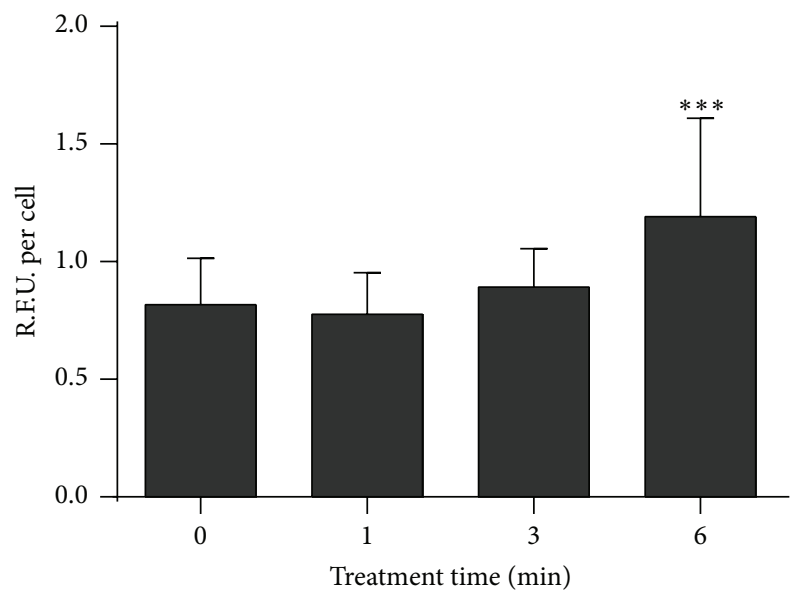

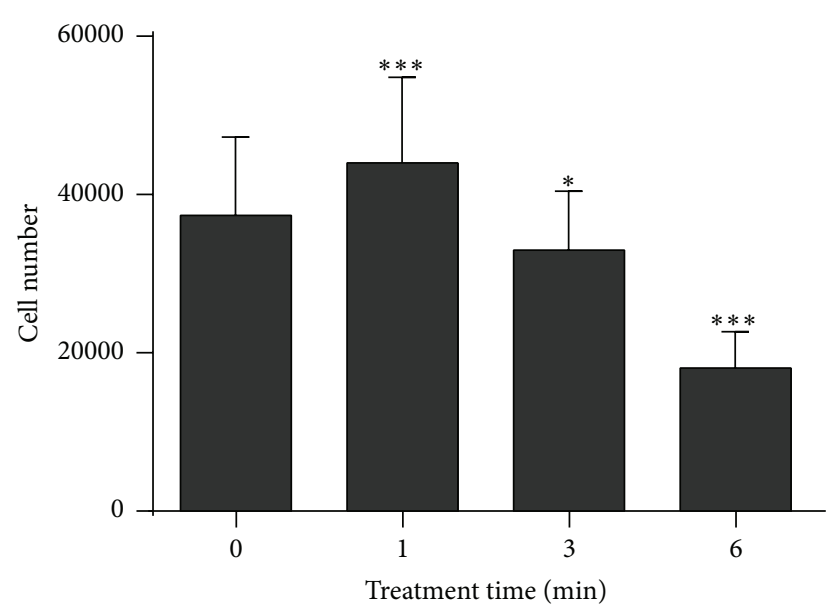

(b)

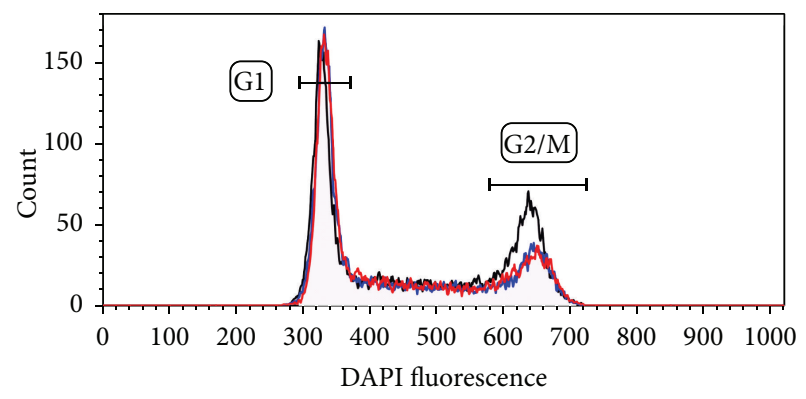

Control

1 min plasma

6 min plasma

(c)

(d)

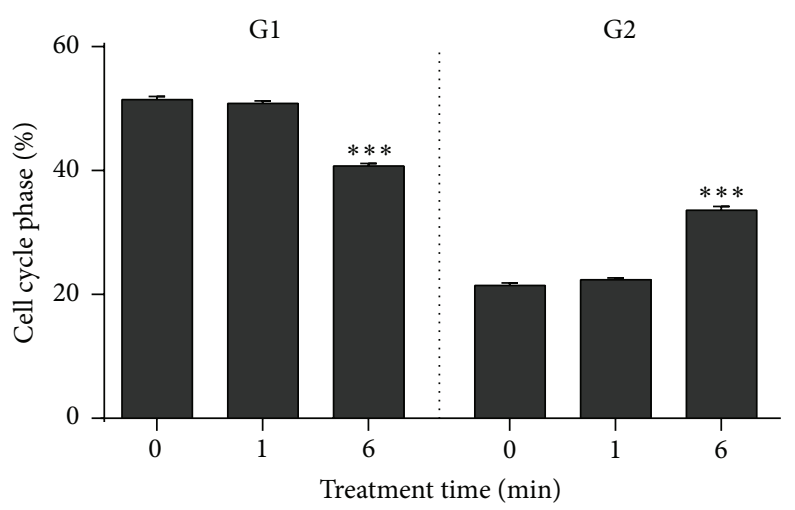

(e)

Figure 4: Analysis of total THP-1 cell metabolism and number. THP-1 monocytes were plasma-treated, and after $72 \mathrm{~h}$ the total metabolic activity was assessed in a microplate reader using the resazurin assay (a). Viable cell numbers were determined of the same samples (b), and the metabolic activity per cell was calculated (c). Twenty-four hours after plasma treatment, cells were subjected to cell cycle analysis (d) and quantitatively compared to each other (e). Data are shown as one representative (d) or mean + S.E. (a, b, c, and e) of three independent experiments. 


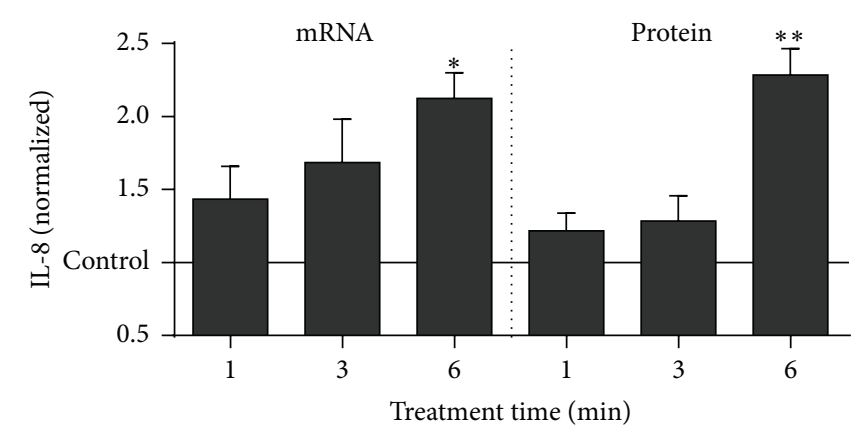

(a)

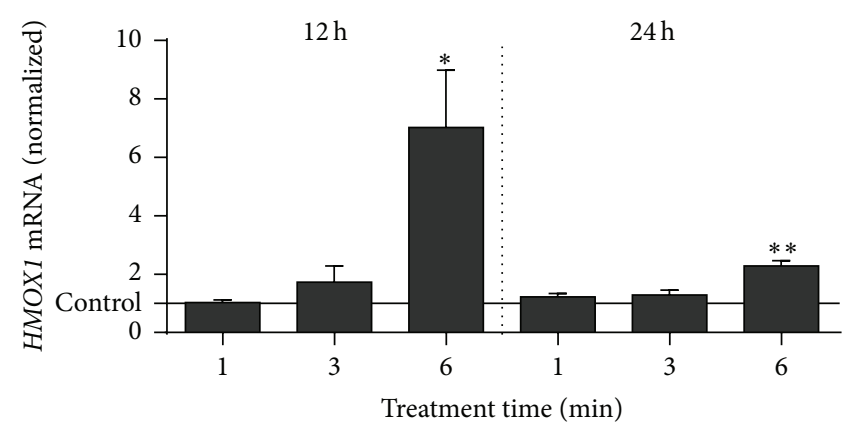

(b)

FIGURE 5: Analysis of THP-1 cell IL-8 and HMOX1 expression. THP-1 monocytes were plasma-treated, and after $24 \mathrm{~h} I L-8$ expression and its secretion were analyzed by real-time PCR and ELISA, respectively. Expression of HMOX1 was examined $12 \mathrm{~h}$ and $24 \mathrm{~h}$ after treatment using real-time PCR (b). Data are presented as mean + S.E. of three independent experiments.

However, in contrast to human keratinocytes [56], oxidative stress response like nuclear factor erythroid 2-related factor (Nrf2) regulated response was not observed as indicated by unchanged $\mathrm{NAD}(\mathrm{P}) \mathrm{H}$ dehydrogenase (quinone) 1 (NQO1) or carbonyl reductase (NADPH) 1 (CBR1) expression (data not shown). Instead, retinoic acid (RA) signaling was activated as shown by cellular retinoic acid binding protein 1 (CRABP1) expression (Table 1). Corroborating our findings, RA signaling in monocytes has been associated with a slowdown of cell cycle progression and a stimulation of cell differentiation [57, 58]. Additionally, RA signaling plays a role in the oxidative stress response and CRABP1 expression may reflect a reaction towards the reduced SOD2 levels [59].

We identified YY1 to be strongly controlled by plasma. In the human T cell line Jurkat, the IFN- $\gamma$ cytokine promoter is under control of YY1 [60]. Malondialdehyde-induced ROS stress was found to highly upregulate YY1 expression in Jurkat cells which was subsequently associated with a marked increase of $I L-8$ mRNA and its release [61]. Strikingly, YY1 is positively regulated by products of $\mathrm{HO}-1$, such as carbon monoxide [62], and HMOX1 upregulation was previously found in plasma-treated keratinocytes [56]. Both molecules are associated with inflammation and we asked next whether their expression was affected following exposure to plasma.

3.4. Plasma Treatment Induced Expression of IL-8 and $H M O X 1$. In the inflammatory phase of wound healing, the main function of the proinflammatory chemokine IL-8 (CXCL8) is the attraction of phagocytes from the blood to the site of injury [63]. Exposure of THP-1 monocytes to plasma led to the presence of higher copy numbers of $I L-8$ mRNA (Figure 5(a)). This correlated with an increase in secretion of IL-8 (Figure 5(b)) while no release or no change in the release of other inflammation-associated molecules (IL-1 $\beta$, IL-6, IL10, IL-17A, IL-22, GM-CSF, INF $\gamma$, TNF $\alpha$, and TGF $\beta$ ) could be observed (data not shown). IL-8 is also secreted by primary monocytes and macrophages but is not associated with autocrine effects on these cells [64], making a contribution of this molecule to other results of this study unlikely. Substantiating our results, antioxidants were found to decrease steady state ROS and IL-8 levels [65] while increased ROS trigger IL-8 expression in primary monocytes/macrophages [66].
Next to IL-8, HMOX1 was significantly upregulated after exposure to plasma (Figure 5(b)). The myeloid cell-specific enzyme HO-1 protects against the cytotoxicity of oxidative stress and mediates immunomodulatory and anti-inflammatory properties [67] via the oxidation of free heme under generation of the products carbon monoxide, biliverdin, and iron [68]. It is upregulated during oxidative stress [69] and hypothesized to be central in the protection and homeostatic reestablishment in numerous pathological conditions [70]. Ferritin, a scavenger of free iron, is coinduced with HMOX1 [71], which may provide a beneficial side effect via, for example, reduced hydroxyl radical generation through the Fenton reaction. Importantly, HO-1 expression was shown to increase the number of mitochondria and total metabolic activity in cardiac cells [72] which corroborates our findings in THP-1 monocytes (Figures 3(f) and 4(c)).

3.5. Study Limitations. Following exposure to cold physical plasma, the widely recognized cell line THP-1 monocytes were used in this study to investigate their biological responses. This includes the identification of their proteomic profile using SILAC mass spectrometry which requires proliferating cells. Yet, owing to the altered ROS-signaling in THP-1 cells [33], the findings identified in this work may not fully represent the redox response in other cell types following exposure to plasma. Moreover, studying the neoplastic THP-1 cells may provide an only imperfect model to mimic responses of wound-resident monocytes/macrophages to plasma. This especially accounts for the changes observed in metabolic activity and cell proliferation as macrophages at the wound site derive from monocyte differentiation rather than cell division [73].

\section{Summary}

Via generation of ROS/RNS, treatment with cold physical plasma may be beneficial in redox-related diseases, such as impaired wound healing. Using THP-1 monocytes as a model, we investigated the oxidative challenge provided by the plasma to these cells. Although plasma induced changes in the intracellular redox status, it only modestly compromised their viability. Short plasma treatment stimulated THP-1 
monocyte growth while longer exposure increased cell size, mitochondrial content, and metabolic activity. Global protein expression analysis revealed an increase in protein synthesis, degradation, and folding processes indicative of both plasmamediated protein stress response and changes in protein expression pattern. A moderate oxidative stress response was detected, yet not via Nrf2 signaling. Changes in RA signaling, YY1, and IRF8 expression suggested the activation of cell differentiation events. At long exposure times, plasma upregulated the expression of IL-8 (but not other inflammatory cytokines) and HMOX1 which are both involved in inflammatory processes, such as wounds. Altogether, THP-1 monocytes mounted a distinct response to plasma which was manifested by alterations of their metabolic activity and inflammatory potential. Our results exemplify the delicate balance of cellular redox control and suggest a role of low-dose redox modulation in wound-related cells which is aimed at being triggered by cold plasma in redox-based diseases.

\section{Abbreviations}

$\begin{array}{ll}\text { IL-8: } & \text { Interleukin-8 } \\ \text { HMOX1, HO-1: } & \text { Heme oxygenase 1 } \\ \text { YY1: } & \text { Yin Yang 1 } \\ \text { SOD: } & \text { Superoxide dismutase. }\end{array}$

\section{Conflict of Interests}

The authors declare that no conflict of interests exists.

\section{Acknowledgments}

The authors acknowledge the support of Lena Bundscherer who generated the HMOX1 and $I L-8$ expression data. This work was funded by the German Federal Ministry of Education and Research (Grant no. 03Z2DN11) and by Ministry of Education, Science and Culture of the State of MecklenburgWestern Pomerania and European Union, European Social Fund (Grants nos. AU 11038 and ESF/IV-BM-B35-0010/13).

\section{References}

[1] D. B. Graves, "The emerging role of reactive oxygen and nitrogen species in redox biology and some implications for plasma applications to medicine and biology," Journal of Physics D: Applied Physics, vol. 45, no. 26, Article ID 263001, 2012.

[2] K. D. Weltmann, E. Kinde, T. von Woedtke, M. Hähnel, M. Stieber, and R. Brandenburg, "Atmospheric pressure plasma sources-prospective tools for plasma medicine," Pure and Applied Chemistry, vol. 82, no. 6, pp. 1223-1237, 2010.

[3] K.-D. Weltmann, M. Polak, K. Masur, T. von Woedtke, J. Winter, and S. Reuter, "Plasma processes and plasma sources in medicine," Contributions to Plasma Physics, vol. 52, no. 7, pp. 644-654, 2012.

[4] K.-D. Weltmann, E. Kindel, R. Brandenburg et al., "Atmospheric pressure plasma jet for medical therapy: plasma parameters and risk estimation," Contributions to Plasma Physics, vol. 49, no. 9, pp. 631-640, 2009.
[5] S. Bekeschus, S. Iseni, S. Reuter, K. Masur, and K.-D. Weltmann, "Nitrogen shielding of an argon plasma jet and its effects on human immune cells," IEEE Transactions on Plasma Science, vol. 43, no. 3, pp. 776-781, 2015.

[6] A. Schmidt-Bleker, J. Winter, S. Iseni, M. Dünnbier, K.-D. Weltmann, and S. Reuter, "Reactive species output of a plasma jet with a shielding gas device-combination of FTIR absorption spectroscopy and gas phase modelling," Journal of Physics D: Applied Physics, vol. 47, no. 14, Article ID 145201, 2014.

[7] S. Vandersee, H. Richter, J. Lademann et al., "Laser scanning microscopy as a means to assess the augmentation of tissue repair by exposition of wounds to tissue tolerable plasma," Laser Physics Letters, vol. 11, no. 11, Article ID 115701, 2014.

[8] G. Isbary, W. Stolz, T. Shimizu et al., "Cold atmospheric argon plasma treatment may accelerate wound healing in chronic wounds: results of an open retrospective randomized controlled study in vivo," Clinical Plasma Medicine, vol. 1, no. 2, pp. 25-30, 2013.

[9] F. Brehmer, H. A. Haenssle, G. Daeschlein et al., "Alleviation of chronic venous leg ulcers with a hand-held dielectric barrier discharge plasma generator (PlasmaDerm VU-2010): results of a monocentric, two-armed, open, prospective, randomized and controlled trial (NCT01415622)," Journal of the European Academy of Dermatology and Venereology, vol. 29, no. 1, pp. 148155, 2015.

[10] J. E. Park and A. Barbul, "Understanding the role of immune regulation in wound healing," The American Journal of Surgery, vol. 187, no. 5, pp. 11S-16S, 2004.

[11] I. V. Klyubin, K. M. Kirpichnikova, and I. A. Gamaley, "Hydrogen peroxide-induced chemotaxis of mouse peritoneal neutrophils," European Journal of Cell Biology, vol. 70, no. 4, pp. 347-351, 1996.

[12] M. P. Rodero and K. Khosrotehrani, "Skin wound healing modulation by macrophages," International Journal of Clinical and Experimental Pathology, vol. 3, no. 7, pp. 643-653, 2010.

[13] K. Rosner, C. Ross, T. Karlsmark, A. A. Petersen, F. Gottrup, and G. L. Vejlsgaard, "Immunohistochemical characterization of the cutaneous cellular infiltrate in different areas of chronic leg ulcers," APMIS, vol. 103, no. 4, pp. 293-299, 1995.

[14] B. M. Delavary, W. M. van der Veer, M. van Egmond, F. B. Niessen, and R. H. J. Beelen, "Macrophages in skin injury and repair," Immunobiology, vol. 216, no. 7, pp. 753-762, 2011.

[15] S. Barrientos, O. Stojadinovic, M. S. Golinko, H. Brem, and M. Tomic-Canic, "Growth factors and cytokines in wound healing," Wound Repair and Regeneration, vol. 16, no. 5, pp. 585-601, 2008.

[16] M. Exner, E. Minar, O. Wagner, and M. Schillinger, "The role of heme oxygenase-1 promoter polymorphisms in human disease," Free Radical Biology \& Medicine, vol. 37, no. 8, pp. 1097-1104, 2004.

[17] E. Engelhardt, A. Toksoy, M. Goebeler, S. Debus, E.-B. Bröcker, and R. Gillitzer, "Chemokines IL-8, GRO $\alpha$, MCP-1, IP-10, and mig are sequentially and differentially expressed during phasespecific infiltration of leukocyte subsets in human wound healing," The American Journal of Pathology, vol. 153, no. 6, pp. 1849-1860, 1998.

[18] K. Turpaev, D. Litvinov, and J. Justesen, "Redox modulation of NO-dependent induction of interleukin 8 gene in monocytic U937 cells," Cytokine, vol. 23, no. 1-2, pp. 15-22, 2003.

[19] C. K. Sen, "Wound healing essentials: let there be oxygen," Wound Repair and Regeneration, vol. 17, no. 1, pp. 1-18, 2009. 
[20] C. K. Sen, "The general case for redox control of wound repair," Wound Repair and Regeneration, vol. 11, no. 6, pp. 431-438, 2003.

[21] D. B. Graves, "Oxy-nitroso shielding burst model of cold atmospheric plasma therapeutics," Clinical Plasma Medicine, vol. 2, no. 2, pp. 38-49, 2014.

[22] S. Bekeschus, K. Masur, J. Kolata et al., "Human mononuclear cell survival and proliferation is modulated by cold atmospheric plasma jet," Plasma Processes and Polymers, vol. 10, no. 8, pp. 706-713, 2013.

[23] K. Wende, P. Williams, J. Dalluge et al., "Identification of the biologically active liquid chemistry induced by a nonthermal atmospheric pressure plasma jet," Biointerphases, vol. 10, no. 2, 2015.

[24] S. Kalghatgi, C. M. Kelly, E. Cerchar et al., "Effects of nonthermal plasma on mammalian cells," PLoS ONE, vol. 6, no. 1, Article ID e16270, 2011.

[25] P. Lukes, E. Dolezalova, I. Sisrova, and M. Clupek, "Aqueousphase chemistry and bactericidal effects from an air discharge plasma in contact with water: evidence for the formation of peroxynitrite through a pseudo-second-order post-discharge reaction of $\mathrm{H}_{2} \mathrm{O}_{2}$ and $\mathrm{HNO}_{2}$," Plasma Sources Science and Technology, vol. 23, no. 1, Article ID 015019, 2014.

[26] K. Wende, S. Reuter, T. von Woedtke, K.-D. Weltmann, and K. Masur, "Redox-based assay for assessment of biological impact of plasma treatment," Plasma Processes and Polymers, vol. 11, no. 7, pp. 655-663, 2014.

[27] S. Bekeschus, J. Kolata, A. Müller et al., "Differential viability of eight human blood mononuclear cell subpopulations after plasma treatment," Plasma Medicine, vol. 3, no. 1-2, pp. 1-13, 2013.

[28] K. Wende, A. Barton, S. Bekeschus et al., "Proteomic tools to characterize non-thermal plasma effects in eukaryotic cells," Plasma Medicine, vol. 3, no. 1-2, pp. 81-95, 2013.

[29] K.-I. Setsukinai, Y. Urano, K. Kakinuma, H. J. Majima, and T. Nagano, "Development of novel fluorescence probes that can reliably detect reactive oxygen species and distinguish specific species," Journal of Biological Chemistry, vol. 278, no. 5, pp. 31703175, 2003.

[30] S. Bekeschus, J. Kolata, C. Winterbourn et al., "Hydrogen peroxide: a central player in physical plasma-induced oxidative stress in human blood cells," Free Radical Research, vol. 48, no. 5, pp. 542-549, 2014.

[31] B. Halliwell and J. M. C. Gutteridge, "Biologically relevant metal ion-dependent hydroxyl radical generation. An update," FEBS Letters, vol. 307, no. 1, pp. 108-112, 1992.

[32] M. B. Hampton and S. Orrenius, "Redox regulation of apoptotic cell death in the immune system," Toxicology Letters, vol. 102103, pp. 355-358, 1998.

[33] P. S. Hole, J. Zabkiewicz, C. Munje et al., "Overproduction of NOX-derived ROS in AML promotes proliferation and is associated with defective oxidative stress signaling," Blood, vol. 122, no. 19, pp. 3322-3330, 2013.

[34] A. Morales, C. García-Ruiz, M. Miranda et al., "Tumor necrosis factor increases hepatocellular glutathione by transcriptional regulation of the heavy subunit chain of $\gamma$-glutamylcysteine synthetase," The Journal of Biological Chemistry, vol. 272, no. 48, pp. 30371-30379, 1997.

[35] J. R. Gasdaska, M. Berggren, and G. Powis, "Cell growth stimulation by the redox protein thioredoxin occurs by a novel helper mechanism," Cell Growth and Differentiation, vol. 6, no. 12, pp. 1643-1650, 1995.
[36] C. Mueller, S. Baudler, H. Welzel, M. Böhm, and G. Nickenig, "Identification of a novel redox-sensitive gene, Id3, which mediates Angiotensin II-induced cell growth," Circulation, vol. 105, no. 20, pp. 2423-2428, 2002.

[37] G.-S. Seo, S.-H. Lee, S.-C. Choi et al., "Iron chelator induces THP-1 cell differentiation potentially by modulating intracellular glutathione levels," Free Radical Biology \& Medicine, vol. 40, no. 9, pp. 1502-1512, 2006.

[38] T. E. DeCoursey and V. V. Cherny, "II. Voltage-activated proton currents in human THP-1 monocytes," The Journal of Membrane Biology, vol. 152, no. 2, pp. 131-140, 1996.

[39] A. Eckhardt, N. Gerstmayr, K.-A. Hiller et al., "TEGDMAinduced oxidative DNA damage and activation of ATM and MAP kinases," Biomaterials, vol. 30, no. 11, pp. 2006-2014, 2009.

[40] P. A. Kramer, S. Ravi, B. Chacko, M. S. Johnson, and V. M. Darley-Usmar, "A review of the mitochondrial and glycolytic metabolism in human platelets and leukocytes: implications for their use as bioenergetic biomarkers," Redox Biology, vol. 2, no. 1, pp. 206-210, 2014.

[41] S. Moncada and J. D. Erusalimsky, "Does nitric oxide modulate mitochondrial energy generation and apoptosis?" Nature Reviews Molecular Cell Biology, vol. 3, no. 3, pp. 214-220, 2002.

[42] E. H. Sarsour, A. L. Kalen, and P. C. Goswami, "Manganese superoxide dismutase regulates a redox cycle within the cell cycle," Antioxidants \& Redox Signaling, vol. 20, no. 10, pp. 16181627, 2014.

[43] C. F. Calkhoven, C. Müller, and A. Leutz, "Translational control of gene expression and disease," Trends in Molecular Medicine, vol. 8, no. 12, pp. 577-583, 2002.

[44] M. Hochstrasser, "Ubiquitin-dependent protein degradation," Annual Review of Genetics, vol. 30, no. 1, pp. 405-439, 1996.

[45] D. L. Swaney, P. Beltrao, L. Starita et al., "Global analysis of phosphorylation and ubiquitylation cross-talk in protein degradation," Nature Methods, vol. 10, no. 7, pp. 676-682, 2013.

[46] M. Scortegagna, K. Ding, Y. Oktay et al., "Multiple organ pathology, metabolic abnormalities and impaired homeostasis of reactive oxygen species in Epasl ${ }^{-/-}$mice," Nature Genetics, vol. 35, no. 4, pp. 331-340, 2003.

[47] A. Shukla, A. M. Rasik, and G. K. Patnaik, "Depletion of reduced glutathione, ascorbic acid, vitamin E and antioxidant defence enzymes in a healing cutaneous wound," Free Radical Research, vol. 26, no. 2, pp. 93-101, 1997.

[48] W.-S. Choi, S.-Y. Yoon, T. H. Oh, E.-J. Choi, K. L. O’Malley, and Y. J. Oh, "Two distinct mechanisms are involved in 6-hydroxydopamine- and $\mathrm{MPP}^{+}$-induced dopaminergic neuronal cell death: role of caspases, ROS, and JNK," Journal of Neuroscience Research, vol. 57, no. 1, pp. 86-94, 1999.

[49] S. Srivastava, B. Chandrasekar, Y. Gu et al., "Downregulation of $\mathrm{CuZn}$-superoxide dismutase contributes to beta-adrenergic receptor-mediated oxidative stress in the heart," Cardiovascular Research, vol. 74, no. 3, pp. 445-455, 2007.

[50] S. Gordon, G. Akopyan, H. Garban, and B. Bonavida, “Transcription factor YY1: structure, function, and therapeutic implications in cancer biology," Oncogene, vol. 25, no. 8, pp. 1125-1142, 2006.

[51] M. Joo, J. G. Wright, N. H. Ning et al., "Yin Yang 1 enhances cyclooxygenase-2 gene expression in macrophages," The American Journal of Physiology-Lung Cellular and Molecular Physiology, vol. 292, no. 5, pp. L1219-L1226, 2007.

[52] T. Tamura, H. Yanai, D. Savitsky, and T. Taniguchi, "The IRF family transcription factors in immunity and oncogenesis," Annual Review of Immunology, vol. 26, pp. 535-584, 2008. 
[53] A. D. Friedman, "Transcriptional control of granulocyte and monocyte development," Oncogene, vol. 26, no. 47, pp. 68166828, 2007.

[54] R. C. Scarpulla, "Nuclear control of respiratory chain expression by nuclear respiratory factors and PGC-1-related coactivator," Annals of the New York Academy of Sciences, vol. 1147, pp. 321334, 2008.

[55] R. C. Scarpulla, R. B. Vega, and D. P. Kelly, "Transcriptional integration of mitochondrial biogenesis," Trends in Endocrinology \& Metabolism, vol. 23, no. 9, pp. 459-466, 2012.

[56] A. Schmidt, S. Dietrich, A. Steuer et al., "Non-thermal plasma activates human keratinocytes by stimulation of antioxidant and phase II pathways," The Journal of Biological Chemistry, vol. 290, no. 11, pp. 6731-6750, 2015.

[57] Q. Chen and A. C. Ross, "Retinoic acid regulates cell cycle progression and cell differentiation in human monocytic THP-1 cells," Experimental Cell Research, vol. 297, no. 1, pp. 68-81, 2004.

[58] S. Han and N. Sidell, "Peroxisome-proliferator-activatedreceptor gamma (PPAR $\gamma)$ independent induction of CD36 in THP-1 monocytes by retinoic acid," Immunology, vol. 106, no. 1, pp. 53-59, 2002.

[59] B. Ahlemeyer, E. Bauerbach, M. Plath et al., "Retinoic acid reduces apoptosis and oxidative stress by preservation of SOD protein level," Free Radical Biology \& Medicine, vol. 30, no. 10, pp. 1067-1077, 2001.

[60] J. Ye, P. Ghosh, M. Cippitelli et al., "Characterization of a silencer regulatory element in the human interferon-gamma promoter," The Journal of Biological Chemistry, vol. 269, no. 41, pp. 2572825734, 1994.

[61] S. Raghavan, G. Subramaniyam, and N. Shanmugam, "Proinflammatory effects of malondialdehyde in lymphocytes," Journal of Leukocyte Biology, vol. 92, no. 5, pp. 1055-1067, 2012.

[62] K. Beck, B. J. Wu, J. Ni et al., "Interplay between heme oxygenase-1 and the multifunctional transcription factor Yin Yang 1 in the inhibition of intimal hyperplasia," Circulation Research, vol. 107, no. 12, pp. 1490-1497, 2010.

[63] T. Matsumoto, K. Yokoi, N. Mukaida et al., "Pivotal role of interleukin- 8 in the acute respiratory distress syndrome and cerebral reperfusion injury," Journal of Leukocyte Biology, vol. 62, no. 5, pp. 581-587, 1997.

[64] B. A. Premack and T. J. Schall, "Chemokine receptors: gateways to inflammation and infection," Nature Medicine, vol. 2, no. 11, pp. 1174-1178, 1996.

[65] S. K. Jain, P. Manna, D. Micinski et al., "In African American type 2 diabetic patients, is vitamin d deficiency associated with lower blood levels of hydrogen sulfide and cyclic adenosine monophosphate, and elevated oxidative stress?" Antioxidants \& Redox Signaling, vol. 18, no. 10, pp. 1154-1158, 2013.

[66] A. Luís, J. D. Martins, A. Silva, I. Ferreira, M. T. Cruz, and B. M. Neves, "Oxidative stress-dependent activation of the eIF $2 \alpha-$ ATFr unfolded protein response branch by skin sensitizer 1fluoro-2,4-dinitrobenzene modulates dendritic-like cell maturation and inflammatory status in a biphasic manner," Free Radical Biology and Medicine, vol. 77, pp. 217-229, 2014.

[67] A. Paine, B. Eiz-Vesper, R. Blasczyk, and S. Immenschuh, "Signaling to heme oxygenase- 1 and its anti-inflammatory therapeutic potential," Biochemical Pharmacology, vol. 80, no. 12, pp. 1895-1903, 2010.

[68] K. D. Poss and S. Tonegawa, "Heme oxygenase 1 is required for mammalian iron reutilization," Proceedings of the National Academy of Sciences of the United States of America, vol. 94, no. 20, pp. 10919-10924, 1997.
[69] C.-Y. Lin, W.-C. Hsiao, C.-J. Huang, C.-F. Kao, and G.-S. W. $\mathrm{Hsu}$, "Heme oxygenase-1 induction by the ROS-JNK pathway plays a role in aluminum-induced anemia," Journal of Inorganic Biochemistry, vol. 128, pp. 221-228, 2013.

[70] F. A. D. T. G. Wagener, C. E. Carels, and D. M. S. Lundvig, "Targeting the redox balance in inflammatory skin conditions," International Journal of Molecular Sciences, vol. 14, no. 5, pp. 9126-9167, 2013.

[71] M. P. Soares and F. H. Bach, "Heme oxygenase-1: from biology to therapeutic potential," Trends in Molecular Medicine, vol. 15, no. 2, pp. 50-58, 2009.

[72] C. A. Piantadosi, M. S. Carraway, A. Babiker, and H. B. Suliman, "Heme oxygenase-1 regulates cardiac mitochondrial biogenesis via nrf2-mediated transcriptional control of nuclear respiratory factor-1," Circulation Research, vol. 103, no. 11, pp. 1232-1240, 2008.

[73] S. Gordon and P. R. Taylor, "Monocyte and macrophage heterogeneity," Nature Reviews Immunology, vol. 5, no. 12, pp. 953-964, 2005. 


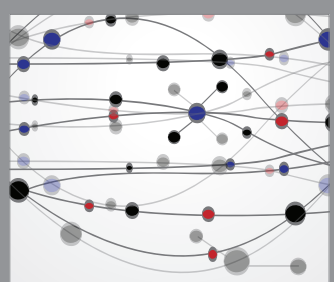

The Scientific World Journal
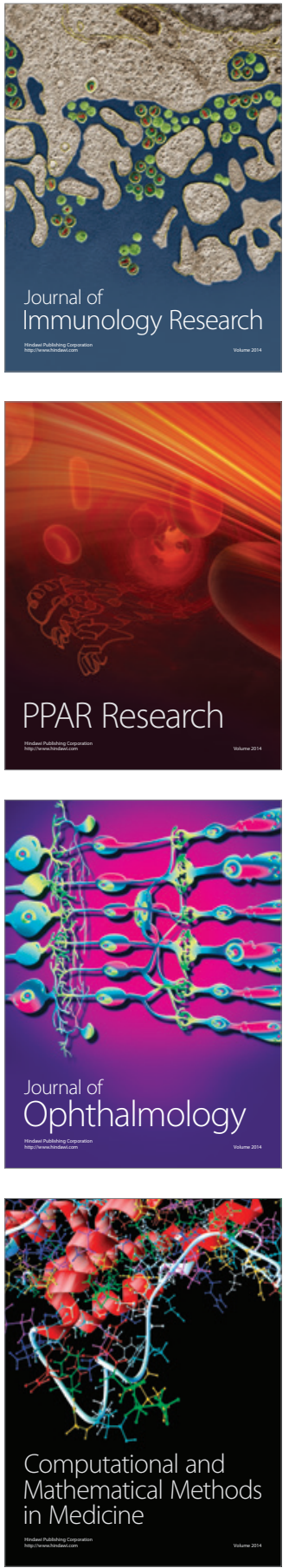

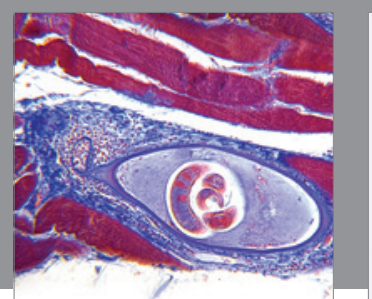

Gastroenterology Research and Practice

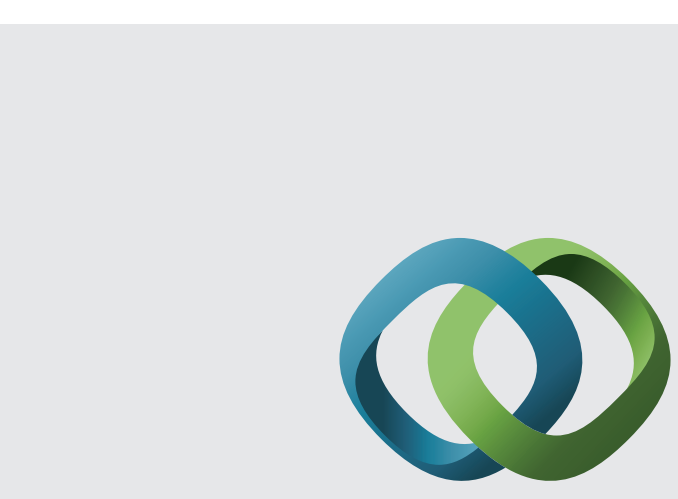

\section{Hindawi}

Submit your manuscripts at

http://www.hindawi.com
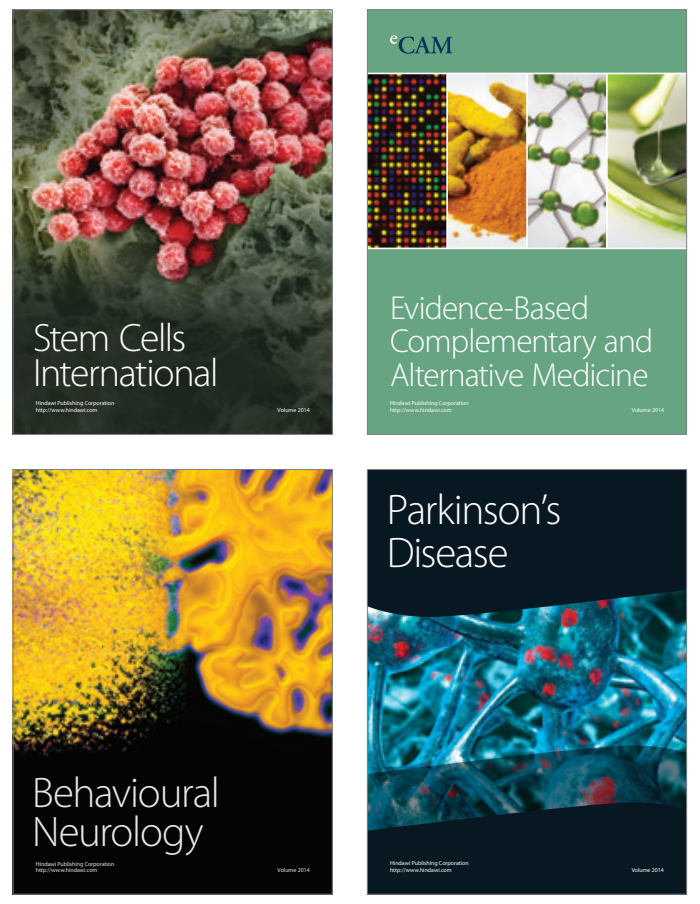
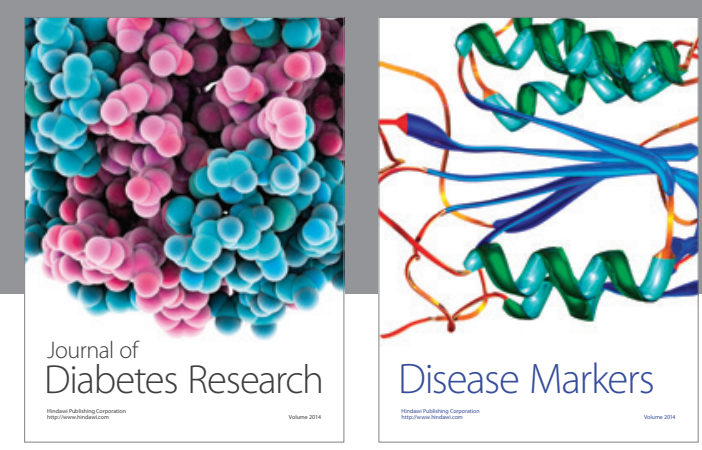

Disease Markers
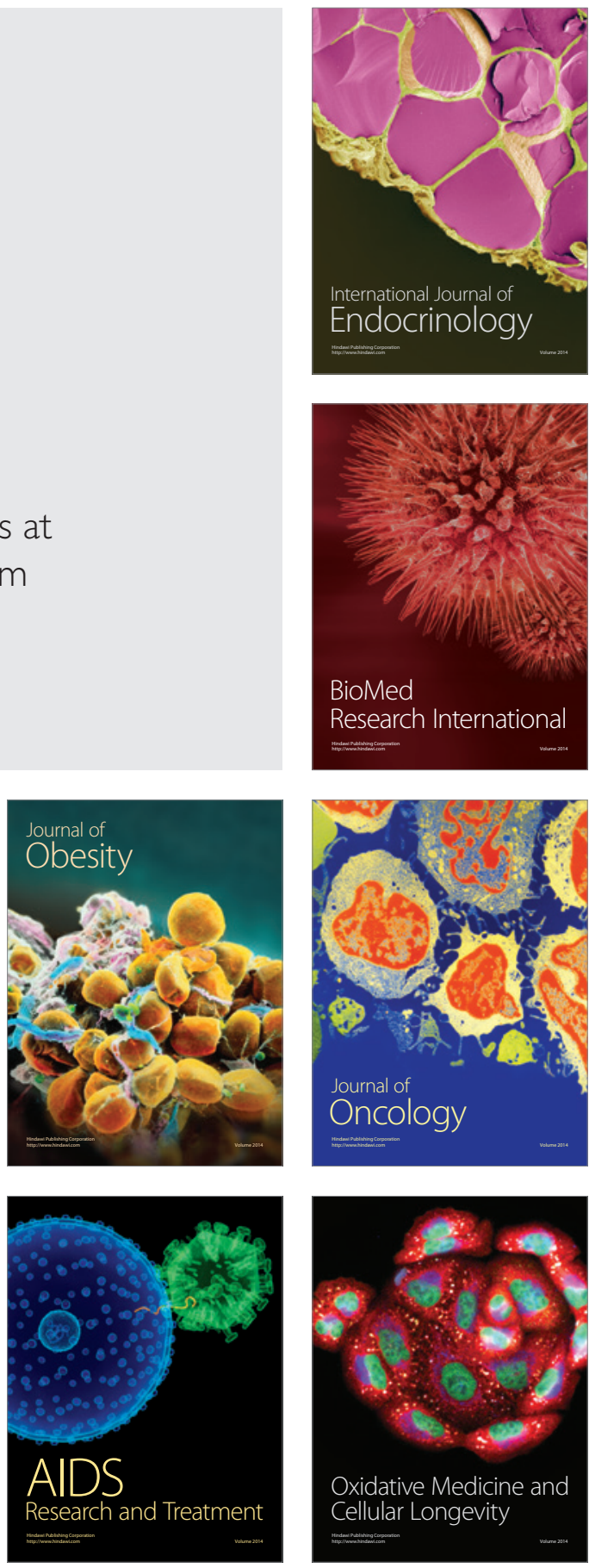